\title{
Downregulation of LSD1 suppresses the proliferation, tumorigenicity and invasion of papillary thyroid carcinoma K1 cells
}

\author{
LING-LING KONG $^{1}$, DONG-MEI MAN ${ }^{2}$, TIAN WANG ${ }^{3}$, GUO-AN ZHANG $^{1}$ and WEN CUI ${ }^{1}$ \\ ${ }^{1}$ Department of Pathology, Basic Science School, Jining Medical University, Jining, Shandong 272067; \\ ${ }^{2}$ Department of Gynecology, Affiliated Hospital of Jining Medical University, Jining, Shandong 272029; \\ ${ }^{3}$ Department of Electrocardiography, The First Affiliated Hospital of Jining Medical University, \\ Jining, Shandong 272111, P.R. China
}

Received December 17, 2014; Accepted January 15, 2016

DOI: $10.3892 / \mathrm{ol} .2016 .4244$

\begin{abstract}
The present study aimed to evaluate the effects of lysine-specific demethylase 1 (LSD1) downregulation, induced by small interfering RNA (siRNA) transfection, on the proliferation, colony formation, migration and invasion of the papillary thyroid carcinoma K1 cell line. The siRNA targeting LSD1 and scrambled non-targeting siRNA were each transfected into papillary thyroid carcinoma K1 cells. Downregulation of LSD1 mRNA and protein level was evaluated by reverse transcription-quantitative polymerase chain reaction, and immunocytochemical (ICC) analysis and western blotting, respectively. A Cell Counting kit- 8 assay was applied to estimate the effect of LSD1-siRNA on cell growth. Migration and invasion abilities were estimated by Transwell chamber assay. A soft agar colony formation assay was performed to estimate the effect of LSD1-siRNA on tumorigenicity in vitro. ICC data showed that LSD1 protein was strongly expressed in the blank and control K1 cells compared with the LSD1-siRNA cells $(\mathrm{F}=15.192, \mathrm{P}<0.01)$. Compared with the control cells, cells transfected with siRNA targeting LSD1 exhibited significant downregulation of LSD1 mRNA $(\mathrm{t}=6.845, \mathrm{P}<0.01)$ and protein $(\mathrm{F}=53.764$, $\mathrm{P}<0.01)$ levels. siRNA targeting LSD1 also downregulated cell proliferation following transfection for 24,48 and $72 \mathrm{~h}$ $(\mathrm{t}=4.777, \mathrm{P}<0.001 ; \mathrm{t}=3.302, \mathrm{P}=0.003$; and $\mathrm{t}=3.017, \mathrm{P}=0.006$, respectively). Compared with the control group, the amount of cell invasion was gradually reduced in the LSD1-siRNA group $(\mathrm{t}=12.301, \mathrm{P}<0.01)$. The number of migrating cells was
\end{abstract}

Correspondence to: Dr Ling-Ling Kong, Department of Pathology, Basic Science School, Jining Medical University, 16 Hehua Street, Jining, Shandong 272067, P.R. China

E-mail: kong001199@yahoo.com

Key words: papillary thyroid carcinoma, lysine-specific demethylase 1, small interfering RNA, Transwell chamber assay, soft agar colony formation assay significantly higher in the negative control group compared with the LSD1-siRNA group $(\mathrm{t}=7.911, \mathrm{P}<0.01)$, and the ability of colony formation in the LSD1-siRNA cells was notably reduced in the soft agar formation assay $(\mathrm{t}=3.612, \mathrm{P}=0.005)$. siRNA targeting LSD1 efficiently inhibits the proliferation, colony formation, migration and invasion of papillary thyroid carcinoma K1 cells.

\section{Introduction}

Thyroid cancer is the most prevalent type of malignant endocrine system cancer (1). Thyroid cancer is histologically classified into papillary, follicular, anaplastic and medullary thyroid cancer, and these subtypes account for $\sim 80,15,2$ and $3 \%$ of all thyroid malignancies, respectively (2). During recent decades, there has been an increasing incidence rate of thyroid cancer observed in several countries, including France (3), USA (4), UK (5) and China (6). The mortality rate of thyroid cancer is relatively low; well-differentiated thyroid carcinoma has a mortality rate of $4 \%$ (7), and the 10 -year relative survival rate for thyroid carcinoma in the USA has improved from $95.4 \%$ in 1983 to $98.6 \%$ in 1999 (8). However, the rate of disease recurrence of this type of cancer is high due to increasing incurability rates (9). Recurrence is identified by fine-needle aspiration biopsy, which is considered valuable for the evaluation of single thyroid tumors (10). Currently, routine neck ultrasonography and monitoring of serum thyroglobulin levels are widely used for recurrence surveillance $(11,12)$. Treatments for thyroid cancer include surgical management, suppression therapy using levothyroxine and adjuvant radioactive iodine (RAI) therapy. RAI ablation has been used routinely, particularly in low-risk patients with thyroid cancer, for $>30$ years (13). However, previous studies have suggested that RAI confers only a minor benefit in reducing the risk of recurrence or mortality $(14,15)$. Considerable studies concerning oncogenic genetic alterations have been performed in thyroid cancer (16-18). Additional knowledge is required regarding the molecular mechanisms of thyroid tumorigenesis, so that targeted treatment may be improved for patients with this disease. 
Lysine-specific demethylase 1 (LSD1) was first identified in 2004 (19). LSD1 has been found to specifically catalyze the demethylation of histone 3 lysine 4 (H3K4) or histone 3 lysine 9 (H3K9) (20), and to demethylate the mono- and di-methyl groups of proteins (19). It has been shown that LSD1 suppresses gene expression by targeting histone H3K4 $(21,22)$, while gene expression is activated by targeting histone H3K9. Although LSD1 is highly expressed in a number of cancer types, its mechanisms of action remain unknown. The present study aimed to evaluate the effects of LSD1 downregulation, induced by small interfering RNA (siRNA) transfection, on the proliferation, colony formation, migration and invasion of the papillary thyroid carcinoma K1 cell line.

\section{Materials and methods}

Cell culture. The human papillary thyroid carcinoma K1 cell line was purchased from the European Collection of Authenticated Cell Cultures (Salisbury, UK). The cells were cultured in Dulbecco's modified Eagle's medium (DMEM; Gibco; Thermo Fisher Scientific, Inc., Waltham, MA, USA) and supplemented with inactivated $10 \%$ fetal bovine serum (FBS; Hyclone; GE Healthcare, Logan, UT, USA), glutamine (2 Mm), penicillin $(100 \mathrm{U} / \mathrm{ml})$ and streptomycin $(100 \mathrm{mg} / \mathrm{ml})$ in a $37^{\circ} \mathrm{C}$ incubator with $5 \% \mathrm{CO}_{2}$.

Transfection of siRNA. The sequences of the siRNA were as follows: LSD1-siRNA sense, 5'-CACAAGGAAAGCUAG AAGATT-3' and anti-sense, 5'-UCUUCUAGCUUUCCUUGU GTT-3'; and scrambled non-targeting siRNA sense, 5'-UUC UCCGAACGUGUCACGUTT-3' and anti-sense, 5'-ACGUGA CACGUUCGGAGAATT-3' (Shanghai GenePharma Co., Ltd., Shanghai, China). K1 cells $\left(1.5 \times 10^{5}\right.$ per well) were seeded in 6-well plates and incubated for $20 \mathrm{~h}$ at $37^{\circ} \mathrm{C}$. Using HiperFect Transfection Reagent (Qiagen GmbH, Wetzlar, Germany), the cells were transfected with either LSD1-siRNA or non-targeting siRNA. Diluted HiperFect Transfection reagent was placed in tube 1 , while diluted siRNA was placed in tube 2 . The two samples were diluted in serum-free medium and incubated at room temperature for $5 \mathrm{~min}$. Next, the reagents in tube 1 were mixed with the siRNA in tube 2 gently by vortexing and incubation at room temperature for $30 \mathrm{~min}$. The mixture was then added to the K1 cells in the 6 -well plates. After $6 \mathrm{~h}$, complete medium with $10 \%$ serum was added to the K1 cells. The transfection medium was replaced after $24 \mathrm{~h}$ with fresh medium.

Immunocytochemistry staining. Immunocy tochemistry staining was applied to observe the expression of LSD1 on the seeded K1 cells on cover slips. Sterilized cover slips were placed into 6-well plates. A total of $100 \mu \mathrm{l} \mathrm{K} 1$ cell suspension was added to each cover slip. After 2-4 h, the K1 cells had adhered in situ. Complete culture medium $(3 \mathrm{ml})$ was added to each well of the 6-well plates and the K1 cells were cultured for another 24-36 h. Each cover slip was gently rinsed three times in phosphate-buffered saline (PBS). Next, the K1 cells were fixed with $4 \%$ (v/v) paraformaldehyde in PBS for $20 \mathrm{~min}$ at room temperature. A brown colored stain was counted as positive expression, while blue staining was regarded as a negative result. An eyepiece graticule facilitated cell counting and was used to count the positive cells at a higher magnification (x400), for which a minimum of 10 fields were used. Each experiment was performed on three replicate samples.

Cell Counting kit-8 assay. Cell Counting kit-8 (CCK8; Dojindo Molecular Technologies Inc., Kumamoto, Japan) was applied to determine the effect of LSD1-siRNA on cell growth. K1 cells $\left(3.6 \times 10^{3}\right)$ transfected with siRNA-LSD1 were seeded into each well of 96-well plates with $100 \mu \mathrm{l}$ complete culture medium. At the same time, $3.6 \times 10^{3} \mathrm{~K} 1$ cells transfected with negative siRNA were also seeded into wells. The $\mathrm{K} 1$ cells were detected using CCK8 after being cultured for another 24, 48 and $72 \mathrm{~h}$, respectively. At the indicated time points, the supernatant was removed and $100 \mu 1$ DMEM containing $10 \mu \mathrm{l}$ CCK8 was added to each well for another $2 \mathrm{~h}$ at $37^{\circ} \mathrm{C}$. The wells with DMEM $(90 \mu \mathrm{l})$ and CCK8 $(10 \mu \mathrm{l})$ were regarded as blank controls. The absorbance was recorded at a wavelength of $450 \mathrm{~nm}$ with a microplate reader (Model 550; Bio-Rad Laboratories Inc., Hercules, CA, USA). Each experiment was performed in sextuplicate and repeated three times.

Soft agar colony formation assay. The $0.7 \%$ soft agar was made in 6-well plates as a base layer and the $0.35 \%$ soft agar was placed on top mixed with suspended cells $\left(1.0 \times 10^{3}\right.$ cells per well). Each layer consisted of $3 \mathrm{ml}$ soft agar containing complete growth medium. The cells were cultured for nearly 14 days until formed colonies were visible. The visible colonies were then counted and images were captured. Each experiment was performed on three replicate samples and repeated three times.

Invasion and migration assays. The invasion ability of the K1 cells was detected in a 24-well Transwell chamber (Corning Inc., Corning, NY, USA) covered with $50 \mu 1$ of $2.0 \mathrm{mg} / \mathrm{ml}$ Matrigel (BD Biosciences, Franklin Lakes, NJ, USA). Cells $\left(1.5 \times 10^{4}\right)$ in $200 \mu \mathrm{l}$ of serum-free medium were added to the upper chamber. DMEM (600 $\mu$ l) supplemented with 15\% FBS filled the lower chamber. Following incubation for $18 \mathrm{~h}$ at $37^{\circ} \mathrm{C}$, the remaining cells on the upper surface of the membrane were swabbed. Methanol was used to fix the invading cells on the lower surface for nearly $20 \mathrm{~min}$, and crystal violet $(0.1 \%)$ was used as a dye. An eyepiece graticule facilitated cell counting of the Transwell cells at a higher magnification $(\mathrm{x} 400)$, for which a minimum of 10 fields were counted. A migration assay was performed using the same steps without the Matrigel layer, and $3 \times 10^{4}$ cells were added to the upper chamber. Each experiment was performed on three replicate samples and repeated three times.

Total RNA isolation, reverse transcription-quantitative polymerase chain reaction ( $R T-q P C R)$. Transfected cells were harvested at the $48 \mathrm{~h}$ time point after transfection. Total RNA was isolated using TRIzol reagent (Invitrogen; Thermo Fisher Scientific). RNA (1 $\mu \mathrm{g})$ was used for the first-strand cDNA synthesis with reverse transcriptase (Promega Corporation, Madison, WI, USA), according to the manufacturer's protocol. Next, RT-qPCR was performed using a SYBR Green qPCR kit (Roche Diagnostics, Indianapolis, IN, USA) according to the manufacturer's protocol, and the LineGene 9600 PCR 
A

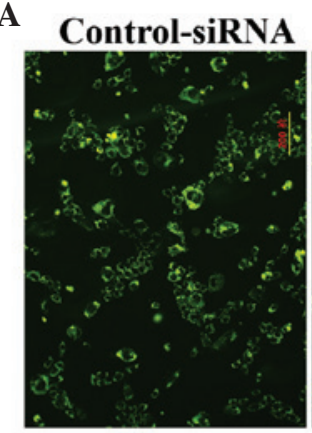

LSD1-siRNA



B

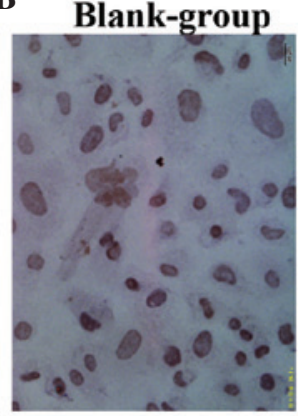

Control-siRNA

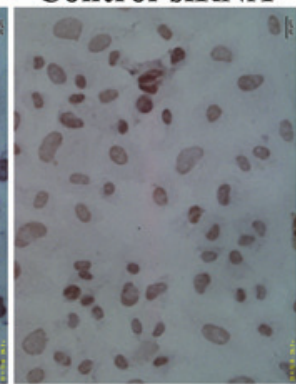

LSD1-siRNA

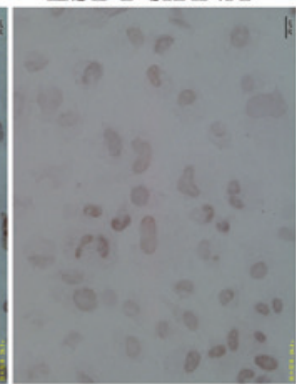

C

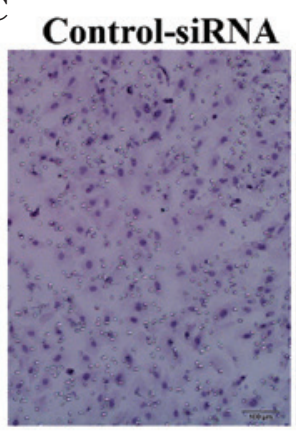

D

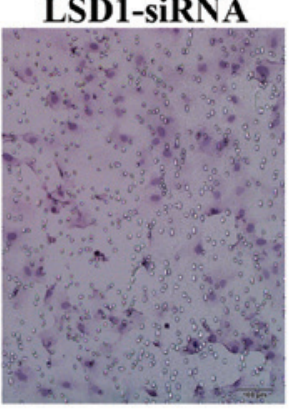

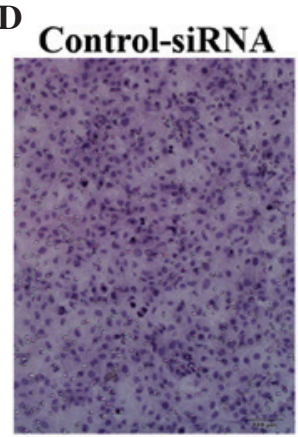

LSD1-siRNA

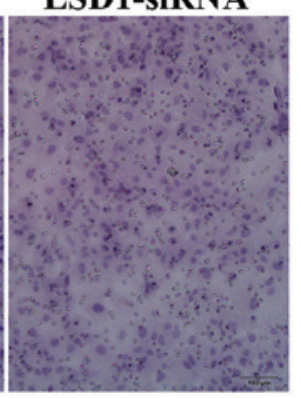

$\mathbf{E}$

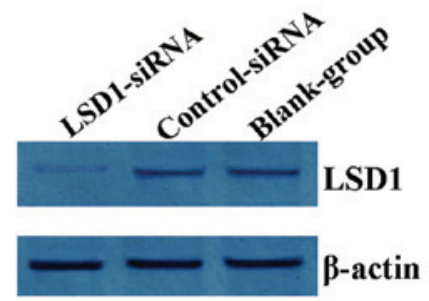

Figure 1. (A) Fluorescent light was found to be emitted uniformly in the cytoplasm upon fluorescence microscopy at a high magnification (x200) in control siRNA and LSD1-siRNA cells. Scale bar, $200 \mu \mathrm{m}$. (B) LSD1 expression and distribution located in the nuclei of the K1 cells. Positive expression of LSD1 was high in cells transfected with negative control siRNA and in the blank control. Expression was significantly downregulated in the LSD1-siRNA cells. 3,3'-Diaminobenzidine and hematoxylin staining; magnification, $x 400$; scale bar, $20 \mu \mathrm{m}$. (C) The number of invading cells and (D) migrating cells in the negative control siRNA group was larger than that for the LSD1-siRNA group. Crystal violet staining; magnification, x100; scale bar, $100 \mu \mathrm{m}$. (E) Western blot analysis implied that compared with the blank and negative control groups, transfection with LSD1-siRNA reduced the expression level of LSD1 protein significantly. LSD1, lysine-specific demethylase 1; siRNA, small interfering RNA.

detection system (Hangzhou Bioer Technology Co., Ltd, Hangzhou, China). Relative mRNA levels of LSD1 were normalized to levels of $\beta$-actin and normalized using the $2^{-\Delta \Delta \mathrm{Cq}}$ method (23). The cycling conditions were as follows: $95^{\circ} \mathrm{C}$ for $5 \mathrm{~min}$ for $1 \mathrm{cycle}$, then $95^{\circ} \mathrm{C}$ for $5 \mathrm{sec}, 50^{\circ} \mathrm{C}$ (annealing) for $30 \mathrm{sec}$ and $72^{\circ} \mathrm{C}$ for $32 \mathrm{sec}$, for 35 cycles. Specific primer pairs were used for LSD1 (forward, 5'-ATGTGTGAGGGA ACTTGCCACC-3' and reverse, 5'-TTGGCACACTCCAGG GCTTTCA-3') and $\beta$-actin (forward, 5'-GAGCAAGAGAGG CATCCTCA-3' and reverse, 5'-AGCCTGGATAGCAACGTA CA-3') (Shanghai GenePharma Co., Ltd.). The experiment was performed on 3 replicate samples and was repeated 3 times.

Western blot analysis. Western blot analysis was performed at the $48 \mathrm{~h}$ time point after transfection. The cells were washed with PBS three times and were lysed with radioimmunoprecipitation assay buffer (Beyotime Institute of Biotechnology, Haimen, China). The concentration of LSD1 protein was determined using a Bicinchoninic Acid Protein Assay kit (Pierce $^{\mathrm{TM}}$; Thermo Fisher Scientific, Inc.). Subsequent to being separated by $10 \%$ sodium dodecyl sulfate-polyacrylamide gel electrophoresis, the LSD1 protein was transferred onto polyvinylidene difluoride membranes. After being blocked with PBS with Tween 20 (PBST) and 5\% dried skimmed milk for $1 \mathrm{~h}$, the membranes were incubated with the monoclonal rabbit anti-human LSD1 primary antibodies (cat. no. 2184; dilution 1:400; Cell Signaling Technology, Inc., Danvers, MA, USA) at $4^{\circ} \mathrm{C}$ for $24 \mathrm{~h}$. The membranes were then washed three times with PBST and incubated with goat anti-rabbit horseradish peroxidase-conjugated immunoglobulin $\mathrm{G}$ secondary antibody (cat. no. BA1054; dilution 1:1,000; BosterBio, Wuhan, China). Proteins were detected using the Enhanced Chemiluminescent Kit for Western (BosterBio).

Statistical analysis. Statistical comparisons of data were evaluated by using Student's t-test (two groups) or an analysis of variance ( $\geq$ three groups), using SPSS 13.0 software (SPSS Inc., Chicago, IL, USA). P $<0.05$ was used to indicate a statistically significant difference.

\section{Results}

Transfection of LSD1-siRNA downregulates the expression of LSD1 in K1 cells. LSD1-siRNA and negative control siRNA were transfected into the papillary thyroid carcinoma K1 cells. Fluorescent light was uniformly emitted in the cytoplasm, as detected by fluorescence microscopy (Fig. 1A). Immunocytochemical (ICC) analysis was performed to detect the expression of LSD1 in the three groups of K1 cells, namely the blank, LSD1-siRNA and negative control siRNA groups. The results demonstrated that the transfection of LSD1-siRNA downregulated the expression of LSD1 (Fig. 1B). Higher LSD1 expression was present in the nuclei of the blank and negative control cells compared with the LSD1-siRNA K1 cells $(\mathrm{F}=15.192, \mathrm{P}<0.01)$ (Fig. $2 \mathrm{~A})$, with only weak staining observed on the cover slips for cells with LSD1-siRNA. There was no statistical difference between the blank and negative control groups $(\mathrm{P}>0.05)$. 
Table I. OD value of the proliferation of the K1 cells, as measured by Cell Counting kit- 8 assay (mean \pm standard deviation).

\begin{tabular}{|c|c|c|c|c|c|c|c|c|c|}
\hline \multirow[b]{2}{*}{ Groups } & \multicolumn{3}{|c|}{$24 \mathrm{~h}$} & \multicolumn{3}{|c|}{$48 \mathrm{~h}$} & \multicolumn{3}{|c|}{$72 \mathrm{~h}$} \\
\hline & OD & t-value & $\mathrm{P}$-value & OD & t-value & P-value & OD & t-value & $\mathrm{P}$-value \\
\hline Control siRNA & $0.526 \pm 0.062$ & 4.777 & $<0.001$ & $0.941 \pm 0.075$ & 3.302 & 0.003 & $1.186 \pm 0.050$ & 3.017 & 0.008 \\
\hline LSD1-siRNA & $0.419 \pm 0.047$ & & & $0.796 \pm 0.132$ & & & $1.119 \pm 0.060$ & & \\
\hline
\end{tabular}

OD, optical density; siRNA, small interfering RNA; LSD1, lysine-specific demethylase 1.

A



$\mathbf{D}$

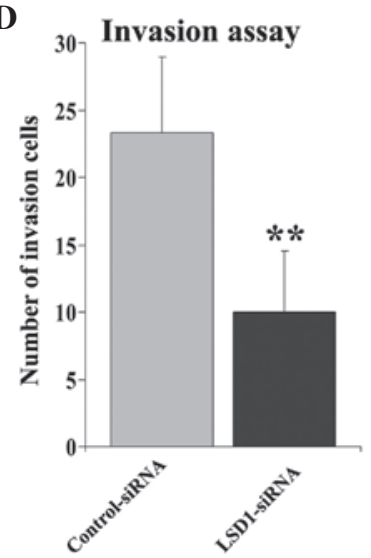

B Expression of LSD1 mRNA C

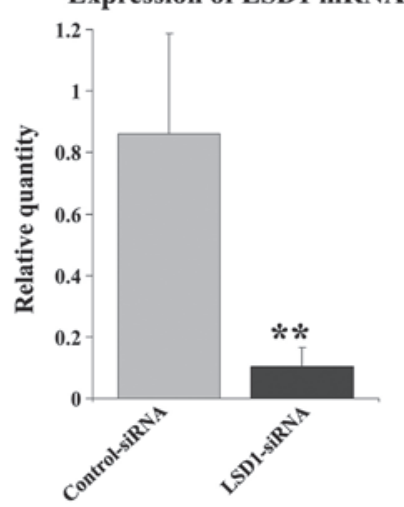

$\mathbf{E}$

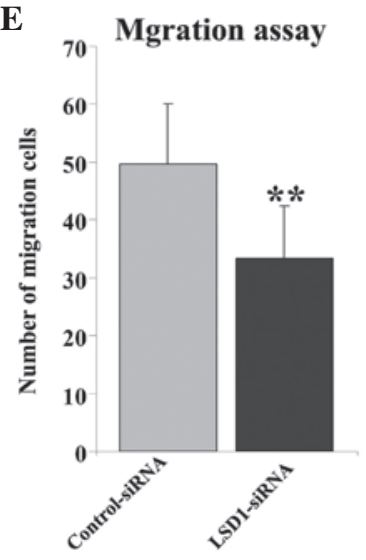

\section{C}

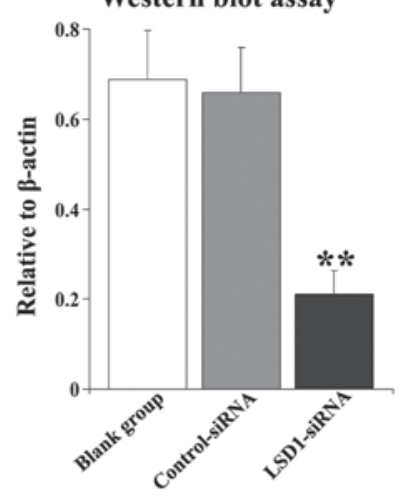

F Soft agar colony formation assay

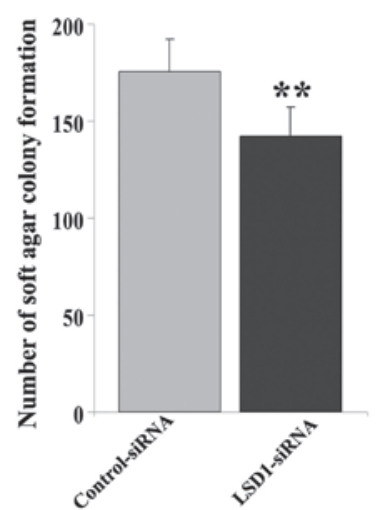

Figure 2.(A) Immunocytochemistry result showing that the expression of LSD1 was downregulated in the LSD1-siRNA cells. (B) Quantification result exhibiting the notable difference between the two groups. (C) Western blot analysis result indicating the marked difference among the three groups. (D) Quantification result revealing that compared with the control cells, the cell invasion ability in the LSD1-siRNA cells was significantly inhibited. (E) Data on migration assay showing that the amount of migrated cells was notable higher for the negative control cells than for the LSD1-siRNA group. (F) Quantification result indicating that compared with the control cells, the ability of colony formation in the LSD1-siRNA cells was notably reduced in the soft agar formation assay. ${ }^{* *} \mathrm{P}<0.01$ vs. blank group (negative control). LSD1, lysine-specific demethylase 1; siRNA, small interfering RNA.

To verify the aforementioned data, the mRNA levels of LSD1 were measured by RT-qPCR using the relative expression value to $\beta$-actin. Transfection of siRNA targeting LSD1 resulted in a significant decrease in the expression of LSD1. The relative values revealed that compared with the control, transfection with LSD1-siRNA statistically decreased the expression level of LSD1 mRNA ( $\mathrm{t}=6.845$, $\mathrm{P}<0.01$ ) (Fig. 2B). Western blot analysis was used to detect the expression level of LSD1 protein using the $\beta$-actin gray value as a reference (Fig. 1E). The results indicated that compared with the blank cells, the LSD1-siRNA transfected cells exhibited a significantly reduced expression level of LSD1 protein ( $\mathrm{F}=53.764, \mathrm{P}<0.01)$ (Fig. 2C), while no statistical difference was found between the blank and scrambled control groups $(\mathrm{P}>0.05)$.

Knockout of LSD1 reduces the proliferation of K1 cells. CCK- 8 was used to investigate the effect of LSD1-siRNA on the proliferation of the $\mathrm{K} 1$ cells. CCK- 8 detects the number of viable cells in proliferation assays. In this process, water-soluble tetrazolium- 8 is reduced by dehydrogenase to produce formazan, which exhibits an orange color, and is dissolved in the culture medium. This means that the amount of formazan is directly proportional to the number of viable cells. In the present study, it was shown that compared with the control group, the optical density of the K1 cells transfected 

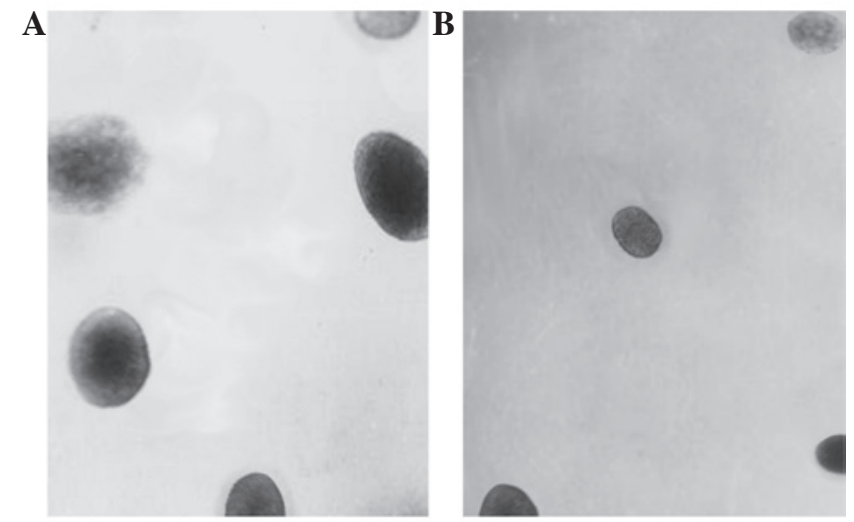

Figure 3. A soft agar colony formation assay was performed to evaluate the effect of LSD1-siRNA on tumorigenicity in vitro. A greater number of colonies were observed in the (A) LSD1-siRNA group compared with the (B) control group. Colonies were observed by the naked eye. LSD1, lysine-specific demethylase 1; siRNA, small interfering RNA.

with LSD1-siRNA at 24, 48 and $72 \mathrm{~h}$ was reduced notably to $0.419 \pm 0.047(\mathrm{t}=4.777, \mathrm{P}<0.001), 0.796 \pm 0.132(\mathrm{t}=3.302$, $\mathrm{P}=0.003)$ and $1.119 \pm 0.060(\mathrm{t}=3.017, \mathrm{P}=0.006)$, respectively (Table I).

Absence of LSD1 inhibits the invasion and migration of $K 1$ cells in vitro. The cell invasion ability was investigated by Transwell assay. Compared with the scrambled control group (Fig. 2D), the amount of invasive cells was reduced from $23.31 \pm 5.65$ to $10.02 \pm 4.54$ following transfection with LSD1-siRNA ( $\mathrm{t}=12.301, \mathrm{P}<0.01$; Fig. 1C). Similar results were observed (Fig. 1D) showing that the number of migrated cells was significantly higher for the negative control cells than for the cells transfected with LSD1-siRNA ( $\mathrm{t}=7.911, \mathrm{P}<0.01$; Fig. 2E).

Loss of LSD1 downregulates the ability of colony formation. A soft agar colony formation assay was performed to evaluate the effect of LSD1-siRNA on tumorigenicity in vitro. Compared with in the control cells, fewer number of colonies were observed (Fig. 3) in the LSD1-siRNA group ( $\mathrm{t}=3.612$, $\mathrm{P}=0.005)$, as shown in Fig. $2 \mathrm{~F}$.

\section{Discussion}

Genetic and epigenetic modifications have been shown to exhibit a significant role in the tumorigenesis and development of cancer. Stable inheritance of epigenetic states is essential for the maintenance of specific functions in cells and tissues (24). Modification of epigenetic states in gene regulation was suggested 40 years ago. Epigenetic alterations are reversible, and significantly contribute to tumor initiation and progression $(24,25)$. Histone methylation is a major determinant of chromatin structure and function, and plays key roles in heterochromatin formation, transcriptional regulation and DNA repair (26). Further study of the epigenetic mechanisms may aid in the identification of a novel cancer-related network, provide attractive targets for cancer and enable novel insights into the biological characteristics of thyroid cancer to be obtained.
LSD1 was first identified in 2004, and suggested that methylation modifications may be reversible (19). Histone methylation shows a dynamic process that is regulated through the alteration of methyl groups by methylases and demethylases. As a member of the monoamine oxidase family, LSD1 catalyzes the specific demethylation of $\mathrm{H} 3 \mathrm{~K} 4 \mathrm{me} 1 / 2$ and $\mathrm{H} 3 \mathrm{~K} 9 \mathrm{me} 1 / 2$ via a process that requires flavin adenine dinucleotide as an essential redox cofactor $(19,21)$. Recent studies have demonstrated that LSD1 exhibits an important role in chromatin remodeling and transcriptional regulation in a number of cancers (27), including breast cancer (28), non-small cell lung cancer (29), gastric cancer (30), ovarian cancer (31), prostate cancer (32), osteosarcoma (33) and neuroblastoma (34). Epigenetic changes in LSD1 have been shown to play a key role in carcinogenesis. LSD1 is regarded as a predictive marker for malignant transformation as the overexpression of LSD1 is associated with poor differentiation and poor survival $(31,34-36)$. LSD1 promotes the growth, invasion and migration of cancer cells (28), while inhibiters of LSD1 suppress the proliferation, migration and invasion of cancer cells $(30,32,37)$.

Thyroid carcinoma is the most common malignancy of the endocrine system and is rapidly increasing in incidence (1). Therefore, clinical markers are urgently required in order to form prognoses and diagnoses for thyroid carcinoma. Our previous study showed that LSD1 plays an important role in the occurrence, malignant transformation and progression of thyroid tumors; the positive expression of LSD1 was used to evaluate the diagnosis of thyroid carcinoma carcinogenesis (38). Since LSD1 shows a strong association with cancer, it may play an important role in the molecular mechanism of thyroid carcinoma. Inhibiters of LSD1, including miRNAs, are used to regulate histone modification $(39,40)$. Therefore, to continue our previous study, the present study analyzed the effects of siRNA targeting LSD1 in papillary thyroid carcinoma K1 cells. A focus was placed on LSD1 in terms of its expression and the effects of this downregulated expression on cell proliferation, colony formation, migration and invasion in vitro. ICC data demonstrated that siRNA targeting LSD1 lowered the expression of LSD1 in the papillary thyroid carcinoma cells; the LSD1 mRNA and LSD1 protein levels were significantly suppressed. siRNA also suppressed the proliferation, and the invasion and migration abilities of the K1 cells. Tumorigenicity in vitro was evaluated by soft agar colony formation assay, and the ability for colony formation was reduced notably following transfection with siRNA.

Overall, the present data revealed that the knockdown of LSD1 expression suppressed the proliferation, migration, invasion and tumorigenicity in papillary thyroid carcinoma cells. Due to the strong association with cancer, LSD1 could be a target for drug discovery, and efficient inhibiters of LSD1 used in the regulation of histone modification could open up a broad field of research in cancer therapy.

\section{Acknowledgements}

The current study was supported by the Natural Science Foundation of Shandong (grant nos. ZR2011HM057 and ZR2009CM070; Shandong, China). 


\section{References}

1. Sherman SI: Thyroid carcinoma. Lancet 361: 501-511, 2003.

2. Hundahl SA, Fleming ID, Fremgen AM and Menck HR: A National Cancer Data Base report on 53,856 cases of thyroid carcinoma treated in the U.S., 1985-1995. Cancer 83: 2638-2648, 1998.

3. Colonna M, Uhry Z, Guizard AV, Delafosse P, Schvartz C, Belot A and Grosclaude P; FRANCIM network: Recent trends in incidence, geographical distribution, and survival of papillarythyroid cancer in France. Cancer Epidemiol 39: 511-518, 2015.

4. Weir HK, Thompson TD, Soman A, Møller B and Leadbetter S: The past, present, and future of cancer incidence in the United States: 1975 through 2020. Cancer 121: 1827-1837, 2015.

5. McNally RJ, Blakey K, James PW, Gomez Pozo B, Basta NO and Hale J: Increasing incidence of thyroid cancer in Great Britain, 1976-2005: Age-period-cohort analysis. Eur J Epidemiol 27: 615-622, 2012.

6. Zhang BL, Sivasubramaniam PG, Zhang Q, Wang J, Zhang B, Gao JD, Tang ZH, Chen GJ, Xie XM, Wang Z, et al: Trends in radical surgical treatment methods for breast malignancies in China: A multicenter 10-year retrospective study. Oncologist 20: 1036-1043, 2015.

7. Lei S, Ding Z, Ge J and Zhao D: Association between prognostic factors and clinical outcome of well-differentiated thyroid carcinoma: A retrospective 10-year follow-up study. Oncol Lett 10: 1749-1754, 2015.

8. Ho AS, Davies L, Nixon IJ, Palmer FL, Wang LY, Patel SG, Ganly I, Wong RJ, Tuttle RM and Morris LG: Increasing diagnosis of subclinical thyroid cancers leads to spurious improvements in survival rates. Cancer 121: 1793-1799, 2015.

9. Tuttle RM, Ball DW, Byrd D, Dilawari RA, Doherty GM, Duh QY, Ehya H, Farrar WB, Haddad RI, Kandeel F, et al; National Comprehensive Cancer Network: Thyroid carcinoma. J Natl Compr Canc Netw 8: 1228-1274, 2010.

10. Huang LY, Lee YL, Chou P, Chiu WY and Chu D: Thyroid fine-needle aspiration biopsy and thyroid cancer diagnosis: A nationwide population-based study. PLoS One 10: e0127354, 2015.

11. Wong CK and Wheeler MH: Thyroid nodules: Rational management. World J Surg 24: 934-941, 2000

12. Spencer C, Petrovic I, Fatemi S and LoPresti J: Serum thyroglobulin $(\mathrm{Tg})$ monitoring of patients with differentiated thyroid cancer using sensitive (second-generation) immunometric assays can be disrupted by false-negative and false-positive serum thyroglobulin autoantibody misclassifications. J Clin Endocrinol Metab 99: 4589-4599, 2014.

13. American Thyroid Association (ATA) Guidelines Taskforce on Thyroid Nodules and Differentiated Thyroid Cancer; Cooper DS, Doherty GM, Haugen BR, Kloos RT, Lee SL, Mandel SJ, Mazzaferri EL, McIver B, Pacini F, Schlumberger M, et al: Revised American Thyroid Association management guidelines for patients with thyroid nodules and differentiated thyroid cancer. Thyroid 19: 1167-1214, 2009.

14. Bourgeois P: A proposition for the use of radioiodine in WDTC management. J Nucl Med 50: 328-329, 2009.

15. Iyer NG, Morris LG, Tuttle RM, Shaha AR and Ganly I: Rising incidence of second cancers in patients with low-risk (T1N0) thyroid cancer who receive radioactive iodine therapy. Cancer 117: 4439-4446, 2011.

16. Beaudenon-Huibregtse S, Alexander EK, Guttler RB, Hershman JM, Babu V, Blevins TC, Moore P, Andruss B and Labourier E: Centralized molecular testing for oncogenic gene mutations complements the local cytopathologic diagnosis of thyroid nodules. Thyroid 24: 1479-1487, 2014.

17. Xing M: Molecular pathogenesis and mechanisms of thyroid cancer. Nat Rev Cancer 13: 184-199, 2013.

18. Saji $M$ and Ringel MD: The PI3K-Akt-mTOR pathway in initiation and progression of thyroid tumors. Mol Cell Endocrinol 321: 20-28, 2010.

19. Shi Y, Lan F, Matson C, Mulligan P, Whetstine JR, Cole PA, Casero RA and Shi Y: Histone demethylation mediated by the nuclear amine oxidase homolog LSD1. Cell 119: 941-953, 2004.

20. Zhang L, He LL, Fu QT and Xu ZF: Selection of reliable reference genes for gene expression studies in the biofuel plant jatropha curcas using real-time quantitative PCR. Int J Mol Sci 14: 24338-24354, 2013
21. Metzger E, Wissmann M, Yin N, Müller JM, Schneider R, Peters AH,GüntherT, Buettner R and Schüle R:LSD1 demethylates repressive histone marks to promote androgen-receptor-dependent transcription. Nature 437: 436-439, 2005.

22. Garcia-Bassets I, Kwon YS, Telese F, Prefontaine GG, Hutt KR, Cheng CS, Ju BG, Ohgi KA, Wang J, Escoubet-Lozach L, et al: Histone methylation-dependent mechanisms impose ligand dependency for gene activation by nuclear receptors. Cell 128 : 505-518, 2007.

23. Livak KJ and Schmittgen TD: Analysis of relative gene expression data using real-time quantitative PCR and the 2(-Delta Delta C(T)) Method. Methods 25: 402-408, 2001.

24. Feinberg AP, Ohlsson R and Henikoff S: The epigenetic progenitor origin of human cancer. Nature Rev Genet 7: 21-33, 2006.

25. Esteller M: Epigenetics in cancer. N Engl J Med 358: 1148-1159, 2008.

26. Zhang Y and Reinberg D: Transcription regulation by histone methylation: Interplay between different covalent modifications of the core histone tails. Genes Dev 15: 2343-2360, 2001.

27. Sorna V, Theisen ER, Stephens B, Warner SL, Bearss DJ, Vankayalapati H and Sharma S: High-throughput virtual screening identifies novel N'-(1-phenylethylidene)-benzohydrazides as potent, specific and reversible LSD1 inhibitors. J Med Chem 56: 9496-9508, 2013

28. Zhang X, Tanaka K, Yan J, Li J, Peng D, Jiang Y, Yang Z, Barton MC, Wen $\mathrm{H}$ and Shi X: Regulation of estrogen receptor $\alpha$ by histone methyltransferase SMYD2-mediated protein methylation. Proc Natl Acad Sci USA 110: 17284-17289, 2013.

29. Lv T, Yuan D, Miao X, Lv Y, Zhan P, Shen X and Song Y: Over-expression of LSD1 promotes proliferation, migration and invasion in non-small cell lung cancer. PLoS One 7: e35065, 2012.

30. Zheng YC, Duan YC, Ma JL, Xu RM, Zi X, Lv WL, Wang MM, Ye XW, Zhu S, Mobley D, et al: Triazole-dithiocarbamate based selective lysine specific demethylase 1 (LSD1) inactivators inhibit gastric cancer cell growth, invasion and migration. J Med Chem 56: 8543-8560, 2013 .

31. Konovalov S and Garcia-Bassets I: Analysis of the levels of lysine-specific demethylase 1 (LSD1) mRNA in human ovarian tumors and the effects of chemical LSD1 inhibitors in ovarian cancer cell lines. J Ovarian Res 6: 75, 2013.

32. Rotili D, Tomassi S, Conte M, Benedetti R, Tortorici M, Ciossani G, Valente S, Marrocco B, Labella D, Novellino E, et al: Pan-histone demethylase inhibitors simultaneously targeting jumonji $\mathrm{C}$ and lysine-specific demethylases display high anticancer activities. J Med Chem 57: 42-55, 2014.

33. Bennani-Baiti IM, Machado I, Llombart-Bosch A and Kovar H: Lysine-specific demethylase 1 (LSD1/KDM1A/AOF2/BHC110) is expressed and is an epigenetic drug target in chondrosarcoma, Ewing's sarcoma, osteosarcoma and rhabdomyosarcoma. Human Pathol 43: 1300-1307, 2012

34. Sakane C, Okitsu T, Wada A, Sagami H and Shidoji Y: Inhibition of lysine-specific demethylase 1 by the acyclic diterpenoid geranylgeranoic acid and its derivatives. Biochem Biophys Res Commun 444: 24-29, 2014.

35. Schulte JH,Lim S, Schramm A, Friedrichs N, Koster J, Versteeg R, Ora I, Pajtler K, Klein-Hitpass L, Kuhfittig-Kulle S, et al: Lysine-specific demethylase 1 is strongly expressed in poorly differentiated neuroblastoma: Implications for therapy. Cancer Res 69: 2065-2071, 2009.

36. Huang Z, Li S, Song W, Li X, Li Q, Zhang Z, Han Y, Zhang X, Miao S, Du R and Wang L: Lysine-specific demethylase 1 (LSD1/KDM1A) contributes to colorectal tumorigenesis via activation of the Wnt/ $\beta$-catenin pathway by down-regulating Dickkopf-1 (DKK1). PLoS One 8: e70077, 2013.

37. Ding D, Liu X and Guo SW: Overexpression of lysine-specific demethylase 1 in ovarian endometriomas and its inhibition reduces cellular proliferation, cell cycle progression and invasiveness. Fertil Steril 101: 740-749, 2014.

38. Kong L, Zhang G, Wang X, Zhou J, Hou S and Cui W: Immunohistochemical expression of RBP2 and LSD1 in papillary thyroid carcinoma. Rom J Morphol Embryol 54: 499-503, 2013.

39. Cherblanc FL, Davidson RW, Di Fruscia P, Srimongkolpithak N and Fuchter MJ: Perspectives on natural product epigenetic modulators in chemical biology and medicine. Nat Prod Rep 30: 605-624, 2013

40. Nana-Sinkam SP and Croce CM: Clinical applications for microRNAs in cancer. Clin Pharmacol Ther 93: 98-104, 2013. 